\title{
Pregnancy Outcome in Fresh and Frozen Embryo Transfer in Women with High Estradiol Levels
}

\section{Archana S*, G Shiva Krishna, Vijalakshmi, Devika Gunasheela}

Sri Ramachandra Institute of Higher Education and Research, Porur, Chennai, India

*Corresponding Author: Archana S, Research Scholar, Department of Human Genetics, Faculty of Biomedical Sciences, Technology and Research, Sri Ramachandra Institute of Higher Education and Research, Porur, Chennai, India.
Received: December 13, 2019

Published: January 06, 2020

(C) All rights are reserved by Archana S., et al.

DOI: 10.31080/ASPE.2020.03.0201

\section{Abstract}

Exogenous elevation of serum estradiol shortly after the time of ovulation is known to reduce the endometrial receptivity in natural cycle. High serumestradiol may affect the synthesis and secretion of glycogen by endometrial epithelial cells. Studies on endometrial morphology, biochemistry and endometrial genomic pattern at the time of implantation showed that high estradiol may negatively affect the endometrial receptivity during infertility treatment. Highestradiol is one of the contributing factors for OHSS.

Controlled Ovarian Hyperstimulation $(\mathrm{COH})$ creates a supraphysiologic environment which affects endometrial receptivity. Frozen embryo transfer avoids supraphysiological environment which alters the endometrial receptivity. Endometrial development can be controlled precisely in frozen embryo transfer cycle than in $\mathrm{COH}$ with gonadotropins.

Keywords: Pregnancy; Estradiol; Frozen Embryo Transfer

\section{Introduction}

High estradiol levels showed lower implantation and pregnancy rates (Forman., et al. 1988; Simon., et al. 1995) where as some other studies (Chenette., et al. 1990) have showed no adverse effects. Elevation of estradiol levels during the First trimester may lead to impaired angiogenesis and results in abnormal placentation.

\section{Objective}

To compare pregnancy outcomes in women with estradiol levels greater than $2500 \mathrm{pg} / \mathrm{ml}$ and number of oocytes obtained $\geq 14$.

\section{Methodology}

Retrospective study conducted at Gunasheela IVF centre from 2011 to 2013. 122 patients were meeting the study criteria. All the patients were $\leq 35$ years old. Total number of oocytes obtained per patient $\geq 14$ and Estradiol levels on the day of HCG $\geq 2500 \mathrm{pg}$ / $\mathrm{ml}$ were the inclusion criteria. Oocyte Donor/recipient cases and Intracytoplasmic sperm injection with donor spermatozoa were excluded. Two groups were included in the study. Group I had 79 patients who had undergone fresh embryo transfer. Group II had 43 patients who had undergone frozen embryo transfer (FET) with no fresh embryo transfer. Fresh embryo transfer was cancelled in group II patients due fluid collection $>70 \mathrm{cc}$ showed in scan in 32 patients and 11 patients had lupride trigger. All the patients in group II had PCOS. Patients in group II was diagnosed as PCOS based on ultrasound findings. Fresh embryo transfer was cancelled in group II due to risk of OHSS. Controlled ovarian stimulation using gonadotropins was done either along with agonist or antagonist protocol. HCG trigger was given when the leading follicle size was $\geq 18 \mathrm{~mm}$ for all the patients in group I and 32patients in group II.11 patients in group II had lupride trigger (leuprolide acetate $1 \mathrm{mg}$ ). Oocyte retrieval was done 34-36hours after HCG injection. Estradiol levels were checked on the day of HCG in all the patients. In Group II, patients had stimulation by straight HRT (hormone replacement Therapy) or Luteal phase down regulation HRT (LPDR+HRT) in Frozen embryo transfer cycle. Ovral-L (levonorgestrel + ethinylestradiol) was given from Day5-day25 in LPDR+HRT for down regulation and followed by administrating GnRH agonist (Lupride) 1/2mg from Day 21 of previous cycle. GnRH agonist (Lupride) was reduced to $1 / 4 \mathrm{mg}$ from Day2/Day 3 of next cycle and Hormone replacement therapy was started with an initial dose of Estradiolvalerate (Progynova) $2 \mathrm{mg}$ and increased by monitoring endometrial measurement. In straight HRT cycle, Estradiolvalerate (Progynova) $2 \mathrm{mg}$ was started from Day3 of the cycle and increased according to the endometrial measurement. FET patients had estimated their estradiol levels when the scan showed tripe line pattern of the endometrium.

Vitrification procedure was done by subjecting the embryos to Equilibration solution for 8-15minutes and vitrification solution 
for 90-110seconds respectively. Warming procedure was done by subjecting the embryos to 1 Molar solution for $1 \mathrm{~min}, 0.5$ Molar solution for $4 \mathrm{~min}$ and HEPES solution for $9 \mathrm{~min}$ respectively.

Statistical analysis was done with chi-square test. Biochemical pregnancy rate, Clinical pregnancy rate, Implantation rate and live birth rate was compared in both groups. P-value $<0.05$ is considered as statistically significant.

\section{Results}

Average age of the patients was $29.6 \pm 3.9$ years and Group II was $30.2 \pm 3.1$ years. 1469 oocytes were retrieved in Group I and 606 oocytes were retrieved in Group II.975 mature oocytes obtained at $0 \mathrm{hrs}$,184immature oocytes had matured after $24 \mathrm{hrs}$ culture in in vitro-maturation (IVM) media (sage) in Group I. Maturation rate was 38.25\% (184/481) in Group I.524 mature oocytes obtained at $0 \mathrm{hrs}, 30$ oocytes had matured after $24 \mathrm{hrs}$ in IVM media in Group II. Maturation rate in Group II was 37.5\% (30/82).Total number of oocytes in Group I was 1159 and total number of oocytes in Group II was 554.Fertilisation rate was 83\% (814/975) in Group I whereas fertilization rate in Group II was 75.81\% (420/554).Cleavage rate was $96 \%$ (784/814) in Group I whereas cleavage rate was $97.61 \%$ (410/420) in Group II as shown in Table 1.

\begin{tabular}{|l|c|c|}
\hline Parameter & Group 1 & Group 2 \\
\hline No. of patients & 79 & 43 \\
\hline Average age (years) & $29.6 \pm 3.9$ & $30.2 \pm 3.1$ \\
\hline No. of oocytes & 1469 & 606 \\
\hline No. of Metaphase II oocytes (o hrs) & 975 & 524 \\
\hline No. of Metaphase II oocytes (24hrs) & 184 & 30 \\
\hline $\begin{array}{l}\text { Maturation rate } \\
(24 \text { hrs) }\end{array}$ & $\begin{array}{c}184 / 481 \\
(38.25 \%)\end{array}$ & $\begin{array}{c}30 / 82 \\
(37.5 \%)\end{array}$ \\
\hline Total no. of Metaphase II oocytes & 1159 & 554 \\
\hline Total no. of Metaphase II oocytes & $1159 / 1469$ & $554 / 606$ \\
$(\%)$ & $(78.89 \%)$ & $(91.41 \%)$ \\
\hline Fertilization rate & $(814 / 1159)$ & $(420 / 554)$ \\
& $70.23 \%$ & $75.81 \%$ \\
\hline Cleavage rate & $(784 / 814)$ & $(410 / 420)$ \\
& $96 \%$ & $97.61 \%$ \\
\hline
\end{tabular}

Table 1

181 embryos were warmed from 43 patients who had undergone frozen embryo transfer. Embryo survival rate was $72.37 \%$ $(131 / 181)$ as shown in table 2 .

Estradiol levels in Group I was $2795 \pm 914.1 \mathrm{pg} / \mathrm{ml}$ at the time of HCG. Estradiol levels at the time of HCG or lupride trigger was $2984 \pm 375.3 \mathrm{pg} / \mathrm{ml}$ and at the time of transfer of frozen thawed embryos was $309 \pm 175 \mathrm{pg} / \mathrm{ml}$ in group II patients. Average number of embryos transferred per patient in Group I and Group II was 2.7 and 2.6 respectively as shown in table 3 .

\begin{tabular}{|l|c|}
\hline \multicolumn{1}{|c|}{ Parameter } & Group 2 \\
\hline Number of embryos thawed per patient & $(181 / 43) 4.2$ \\
\hline Embryo survival rate & $(131 / 181) 72.37 \%$ \\
\hline
\end{tabular}

Table 2

\begin{tabular}{|l|l|l|}
\hline \multicolumn{1}{|c|}{ Parameter } & \multicolumn{1}{c|}{ Group 1 } & \multicolumn{1}{c|}{ Group 2 } \\
\hline Estradiol levels(pg/ml) & $2795 \pm 914.1$ & $309 \pm 175$ \\
\hline Embryos transferred & $(216 / 79) 2.7$ & $(113 / 43) 2.6$ \\
\hline
\end{tabular}

Table 3

Total pregnancy rate in Group I and Group II was $40.5 \%$ and $55.8 \%(p=0.105)$ respectively. Biochemical pregnancy is defined as pregnancy diagnosed by detection of HCG in serum or urine and that does not develop into a clinical pregnancy. Biochemical pregnancy rate in Group I and Group II was $40.5 \%$ and $55.8 \%$ (p= 0.105 ) respectively. Pregnancy diagnosed by ultrasonographic or clinical documentation of at least one foetus with heartbeat is defined as Clinical pregnancy. Clinical pregnancy rate in Group I and Group II was $36.7 \%$ and $48.8 \%(p=0.19$ ) respectively. Implantation rate in Group I and Group II was $22.2 \%$ and $18.8 \%$ ( $p=0.44$ ). Live birth rate in Group I was $20.25 \%$ and in Group II was $44 \%$ (0.005) as shown in table 4.

\begin{tabular}{|l|c|c|c|}
\hline \multicolumn{1}{|c|}{ Parameter } & Group 1 & Group 2 & P-value \\
\hline $\begin{array}{l}\text { Total pregnancy } \\
\text { rate }\end{array}$ & $(32 / 79) 40.5 \%$ & $(24 / 43) 55.8 \%$ & 0.105 \\
\hline $\begin{array}{l}\text { Biochemical } \\
\text { pregnancy rate }\end{array}$ & $(3 / 79) 3.7 \%$ & $(3 / 43) 6.9 \%$ & 0.105 \\
\hline $\begin{array}{l}\text { Clinical Pregnancy } \\
\text { rate }\end{array}$ & $(29 / 79) 36.7 \%$ & $(21 / 43) 48.8 \%$ & 0.19 \\
\hline Implantation Rate & $(48 / 216) 22.2 \%$ & $(26 / 138) 18.8 \%$ & 0.44 \\
\hline Live Birth Rate & $(16 / 79) 20.25 \%$ & $(19 / 43) 44 \%$ & 0.005 \\
\hline
\end{tabular}

\section{Table 4}

\section{Discussion and Conclusion}

This study showed high estradiol levels had an effect on live birth- rate. Estradiol levels for patients who had undergone fresh embryo transfer were $2795 \pm 914.1 \mathrm{pg} / \mathrm{ml}$. They had showed a live birth-rate of $20.25 \%$ (16/79). Frozen embryo transfer had a live birth-rate of $44 \%$ (19/43) and estradiol levels were $309 \pm 175 \mathrm{pg} /$ $\mathrm{ml}$. Total pregnancy rate, clinical pregnancy rate, Implantation rate didn't showed much difference in both groups. Implantation rate in Group I and Group II were $22.2 \%$ and $18.8 \%$ respectively. Live birth rate is statistically significant $(\mathrm{p}<0.005)$. There is a drastic fall in live birth rate in fresh embryo transfer when compared to frozen embryo transfer [1-26].

Decrease in live birth-rate may be due to abnormal placentation. Altered trophoblastic invasion into myometrial and uterine vessels leads to abnormal placentation and results in activation of maternal vasoconstrictors. 
Ovarian stimulation leads to elevated estrogen levels which may affect the endometrium. High estradiol creates a supraphysiological environment which results in decreased trophoblastic invasion of the decidual and myometrial spiral arteries, aberrant cell survival and apoptosis which leads to abnormal placentation. The ultimate consequence of this phenomenon is that these arteries retain the ability to respond to vasoactive stimuli, causing incessant vasoconstriction. During the course of pregnancy, vasoconstriction may lead to suboptimal blood supply to the growing placenta and subsequent spontaneous abortion, stillbirth, small for gestational age (SGA), orpreclampsia (PreE).

During the formation of normal placenta, Trophoblast divides into villous and extra-villous trophoblast after implantation. Cytotrophoblast which acts as a source of proliferative cells gives rise to syncytiotrophoblast and extra villous trophoblast. Syncytiotrophoblast in contact with maternal blood gives rise to villi. Extra-villous trophoblast segregates into trophoblastic shell, interstitial and endovascular cells respectively invading decidua, myometrium and uterine vessels.

Invasion of the trophoblast into maternal tissue leads to remodelling of arterial walls with loss of smooth muscle and associated elastic and collagenous extracellular mass. They will be replaced by unique fibrin based polymeric deposit (fibrinoid). This results in conversion of high resistance low capacity vessels into low resistance high capacity vessels and made independent of maternal vasoconstrictors in normal placentation. Activation of these maternal vasoconstrictors takes place in abnormal placentation which results in spontaneous abortion, stillbirth, SGA or pre E and affects the live birth-rate.

In Conclusion, Frozen embryo transfer is better than fresh embryo transfer in women with estradiol levels greater than $2500 \mathrm{pg} /$ $\mathrm{ml}$ and total number of oocytes obtained greater than 14 .

\section{Bibliography}

1. Imudia AN., et al. "Peak serum estradiol level during controlled ovarian hyperstimulation is associated with increased risk of small for gestational age and preeclampsia in singleton pregnancies after in vitro fertilization". Fertility and Sterility 97 (2012): 1374-1379.

2. Farhi J., et al. "High serum oestradiol concentrations in IVF cycles increase the risk of pregnancy complications related to abnormal placentation". RBM Online 21 (2010): 331-337.

3. Ernest Hung yung., et al. "Human serum estradiol concentrations in fresh IVF cycles do not impair implantation and pregnancy rates in subsequent frozen thawed embryo transfer cycles". 2:250-255.
4. Juan A., et al. "Vasculogenesis and Angiogenesis in the IUGR Placenta”. Seminar on Perinatology 32 (2008): 172-177.

5. John D Aplin. "Implantation, trophoblast differentiation and heamochorial placentation: mechanistic evidence in vivo and invitro". Journal of life sciences 99 (1991): 681-692.

6. Jean Guibourdenche., et al. "Development and hormone functions of placenta". Folia Histochemica et Cytobiologica 47 (2009): 35-42.

7. Matheus Roque., et al. "Fresh embryo transfer versus frozen embryo transfer in in vitro fertilization cycles:a systemic review and meta-analysis". Fertility and Sterility 99 (2013): 156162.

8. Roberts JM. "Endothelial dysfunction in preeclampsia”. Seminars in Reproductive Endocrinology 16 (1998): 5-15.

9. Dixon HG and Robertson WB. "A study of the vessels of the placental bed in normotensive and hypertensive women". Journal of Obstetrics and Gynaecology 65 (1958): 803-809.

10. Albrecht ED., et al. "Suppression of extravillous trophoblast invasion of uterine spiralarteries by estrogen during early baboon pregnancy". Placenta 27 (2006): 483-490.

11. Bonagura TW., et al. "Suppression of extra villoustrophoblast vascular endothelial growth factor expression and uterine spiralartery invasion by estrogen during early baboon pregnancy". Endocrinology 149 (2008): 5078-5087.

12. Urban Waldenstrom., et al. "High pregnancy rates and successful prevention of severe ovarian hyperstimulation syndrome by prolonged coasting' of very hyperstimulated patients: a multicentre study". Human Reproduction 14.2 (1999): 294297.

13. Tal Imbar., et al. "Reproductive outcome of freshor frozenthawed embryo transfer is similar in high-risk patients forovarian hyperstimulation syndrome using GnRH agonist for final oocytematuration and intensive luteal support". Human Reproduction (2012): 1-7.

14. Forouzan Absalan., et al. "Reproductive Outcome Following Thawed Embryo Transfer in Management of Ovarian Hyperstimulation Syndrome". Journal of Reproduction and Infertility 14.3 (2013): 133-137.

15. Carolina O Nastri., et al. "Ovarian hyperstimulation syndrome: pathophysiology and prevention". Journal of Assisted Reproduction and Genetics 27 (2010): 121-128.

16. Golan A., et al. "Ovarian hyperstimulation syndrome: an update review”. Obstetrical and Gynecological Survey 44 (1989): 430-440. 
17. Serour GI., et al. "Complications of medically assisted conception in 3,500 cycles". Fertility and Sterility 70 (1998): 638-642.

18. Morris RS., et al. "Conservative management of ovarian hyperstimulation syndrome". Journal of Reproductive Medicine 40 (1995): 711-714.

19. Hu XL., et al. "High maternal serum estradiol environment in the first trimester is associated with the increased risk of small-for-gestational-age birth". The Journal of Clinical Endocrinology and Metabolism 99 (2014): 2217-2224.

20. Hustin J., et al. "Histological study of the maternoembryonic interface in spontaneous abortion". Placenta 11 (1990): 47786.

21. Suleena Kansal Kalra., et al. "Perinatal morbidity after in vitro fertilization is lower with frozen embryo transfer". Fertility and Sterility 95.2 (2011): 548-553.

22. Michael M Alper., et al. "Ovarian Hyperstimulation Syndrome: Current Views on Pathophysiology, Risk Factors, Prevention, and Management". Journal of Experimental and Clinical Assisted Reproduction 6 (2009): 3.

23. Joseph E Pena., et al. "Supraphysiological estradiol levels do not affect oocyte and embryo quality in oocyte donation cycles". Human Reproduction 17.1 (2002): 83-87.

24. Alexandre U Borbely., et al. "The term basal plate of the human placenta as a source of functional extravillous trophoblast cells". Reproductive Biology and Endocrinology 12 (2014): 7

25. Jemma Evans., et al. "Fresh versus frozen embryo transfer: backing clinical decisions with scientific and clinical evidence". Human Reproduction (2014): 1-14

26. Tal Imbar., et al. "Reproductive outcome of fresh or frozenthawed embryo transfer is similar in high-risk patients forovarian hyperstimulation syndrome using GnRH agonist for final oocyte maturation and intensive luteal support". Human Reproduction (2012): 1-7.

27. James M Roberts., et al. "Maternal Fetal/Placental Interactions and Abnormal Pregnancy Outcomes". Hypertension 49 (2007): 15-16.

\section{Assets from publication with us}

- Prompt Acknowledgement after receiving the article

- Thorough Double blinded peer review

- Rapid Publication

- Issue of Publication Certificate

- High visibility of your Published work

Website: www.actascientific.com/

Submit Article: www.actascientific.com/submission.php

Email us: editor@actascientific.com

Contact us: +919182824667 